\title{
Reducing, by Pulse Width Modulation, the Curing Temperature of a Prototype High-power LED Light Curing Unit
}

\author{
Ta-Ko HUANG, Chun-Cheng HUNG and Chi-Cheng TSAI \\ Graduate Institute of Dental Science, Chung-Ho Memorial Hospital, Kaohsiung Medical University, 100 Tzyou $1^{\text {st }}$ Road, \\ Kaohsiung 807, Taiwan, Republic of China \\ Corresponding author, Dr. Chun-Cheng Hung E-mail:yuchali@ms21.hinet.net
}

Received January 13, 2006/Accepted March 1, 2006

\begin{abstract}
Third-generation LEDs have high irradiance and efficiency, but the associated temperature rise is potentially hazardous to the pulp of teeth. We evaluated, during composite polymerization, the irradiance and temperature rise of a prototype highpower LED light curing unit (LCU) with optimal pulse width modulation (PWM), and then compared the results with four off-the-shelf high-power LCUs. A cavity was prepared in a tooth, and a composite resin layer was applied and cured. For each LCU, the irradiance and temperature changes at the pulp-dentin junction were measured. Microhardness (Vickers hardness) of cured composite samples was measured for each LCU. Our prototype had a final temperature of $36.4 \pm 1.3^{\circ} \mathrm{C}$ and irradiance of $1,182 \pm 1 \mathrm{~mW} / \mathrm{cm}^{2}$. The unit with the highest temperature had a temperature of $48.7 \pm 1.2^{\circ} \mathrm{C}$ and an irradiance of $1,194 \pm 1 \mathrm{~mW} / \mathrm{cm}^{2}$. Based on the results of the present study, it was shown that PWM technology reduced the curing temperature while retaining the polymerization effectiveness of a high-power LED LCU.
\end{abstract}

Key words: Light emitting diode (LED), Light curing units (LCUs), Pulse width modulation (PWM)

\section{INTRODUCTION}

Different light sources have been used in dental light curing units (LCUs) for polymerization of oral biomaterials. Several reports have mentioned that heat generation during the curing process has become a serious matter as it adversely affects the pulp tissue and dental materials ${ }^{1-5)}$. In 1965, it was found that when healthy pulp in rhesus monkeys was heated with only a $5.5^{\circ} \mathrm{C}$ increase, $15 \%$ of the teeth developed necrosis ${ }^{6)}$. These results as well as the findings of Pohto and Scheinin indicated that the critical temperature for irreversible damage to the pulp begins at $42-42.5^{\circ} \mathrm{C}^{7}$. A previous study has shown that, unfortunately, the most curing-effective light sources lead to the highest temperature rise ${ }^{8)}$.

Since the first blue LEDs were introduced to the market ${ }^{9)}$, the LED has been widely used in dental curing devices. In particular, the LED has recently replaced the conventional quartz-tungsten-halogen (QTH) light in dental LCUs for selected oral biomaterials. Some related reports showed that the temperature rise from the LED was not as high as that from the plasma arc and QTH curing lights ${ }^{10,11)}$. However, it must be highlighted that the irradiance of LEDs then was lower than the current LEDs ${ }^{12-14)}$. Some reports have already shown that secondgeneration LEDs have the potential to exceed QTH LCUs in terms of effectiveness if the composites are selected carefully ${ }^{15-17)}$. The output intensity of second-generation LEDs has reached $500 \mathrm{~mW} / \mathrm{cm}^{2,18)}$, but the temperature rise during curing is still not as high as QTH LCUs ${ }^{19,20)}$.
In the latest technology for dental applications, the third-generation high-power LED has replaced the lower-irradiance LED in dental light curing units (LCUs). Its irradiance is well above previous LEDs and exceeds $1,000 \mathrm{~mW} / \mathrm{cm}^{2,18)}$. However, temperature rise with high irradiance in a high-power LED LCU and its effect on pulp and oral biomaterials during the curing process have become an issue that cannot be ignored $^{21,22)}$.

A continuous argon laser can cure composites in a very short time, but due to polymerization shrinkage and heat generation, the clinical use of a powerful laser is limited. On the other hand, a pulsed laser can produce a satisfactory temperature rise and curing depth for dental composite polymerization ${ }^{23)}$. A pulsed laser emits light in individual pulses and hence reduces the heat which is otherwise generated from a high-energy release ${ }^{24)}$. In this connection, the same idea was applied in our present high-power LED prototype with a view to reducing temperature. In a previous study, it was mentioned that pulse width modulation (PWM) by a control circuit with a microprocessor is a powerful technique to control the output power of $\operatorname{LEDs}^{25)}$. This has since become a popular technique for controlling the power intensity of LEDs in non-medical applications.

This study sought to test the hypothesis that using a PWM mode to control the LED output in a prototype high-power LED LCU would result in statistically significant lower polymerization temperature, but with acceptable microhardness for composite fillings when compared with four commercially available high-power LCUs. 


\section{MATERIALS AND METHODS}

Characterization of prototype PWM LED LCU

This study used a Luxeon Dental LXHL-PRD5, U8T, $5 \mathrm{~W}$ high-irradiance high-power LED, with 465-470 $\mathrm{nm}$ wavelength and $700 \mathrm{~mA}$ forwarding current (Lumileds Lights, San Jose, CA, USA). Six different power-up timer programmed 8-bit CMOS microprocessors PIC16C711 with analog-to-digital converter (Microchip Tech. Inc., AZ, USA), an oscillator startup timer, and in-circuit serial programming with a MOSFET transistor were used to make one compatible circuit board, which controlled the electric current output and time intervals after LED activation.

Output of LED was defined by dividing its output into 48 segments per second, which was $21 \mathrm{~ms}$ per segment. Each segment was divided into seven sections of $3 \mathrm{~ms}$ each by the PWM. Six different PWM modes were tested, and their time dependence was checked through wave diagrams by using a digital real-time oscilloscope (TDS 220, Tektronix Inc., OR, USA) (Fig. 1).

The LED probe was mounted with high-power LED fixed on a heat sink, and surrounded by an 8$\mathrm{mm}$ diameter reflector. Six different PWM circuit boards were used for the prototype LCU. They were activated at $6.9 \mathrm{~V}$ DC through the circuit board by a power supply. The LED was placed at the front of the device and activated (Fig. 2). A digital curing

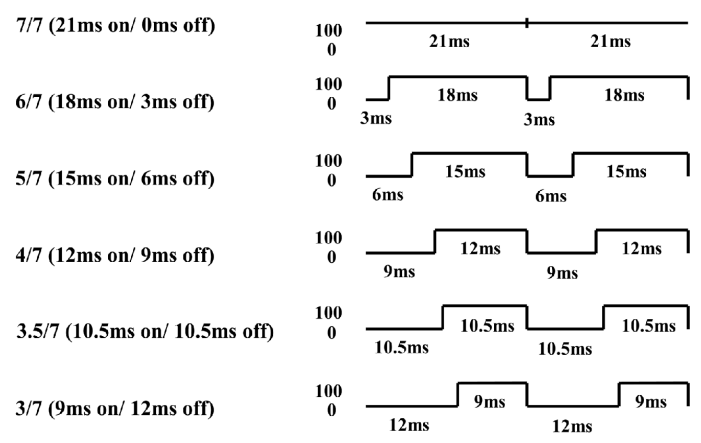

Fig. 1 Wave diagrams and their time dependence of six different PWM modes.

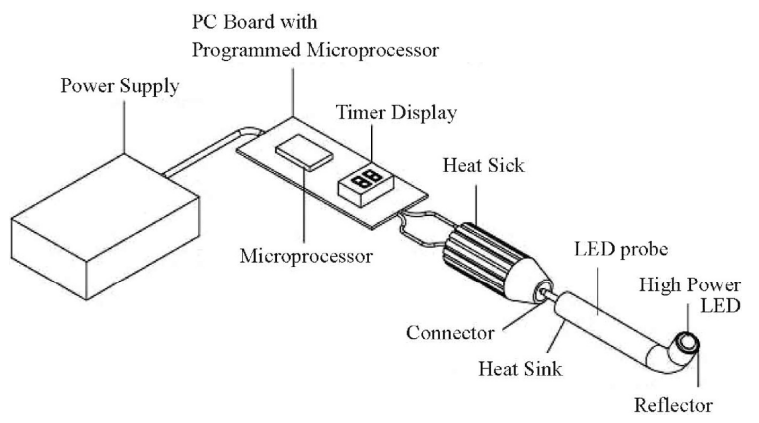

Fig. 2 Schematic drawing of a custom-made PWM LED LCU prototype, in which the LED was placed at the front of the device. radiometer $^{1,2)}$ (Cure Rite, Model No. 644726, Serial No. 7072, Dentsply Caulk, DE, USA) was used to measure the irradiance of the LED output directly from the LED probe after activation. Measurement was repeated five times with the LED powered down and reactivated between measurements.

A light-cured hybrid dental composite resin (Z250 shade A2, Lot No.4YJ, 3M ESPE, St. Paul, MN, USA) was used as the test material. The main components of Z250 were urethane dimethacrylate (UDMA), 2,2-bis[4-(2-hydroxy-3-methacryloyloxypropoxy)phenyl]propane (Bis-GMA), ethoxylated bisphenol-A-dimethacrylate (Bis-EMA), and zirconia/ silica filler of $0.01-3.5 \mu \mathrm{m}$ particle size at 66 volume\%, as well as camphorquinone as the only photoinitiator. For specimen preparation, a cavity $4 \mathrm{~mm}$ in diameter and $2 \mathrm{~mm}$ in depth was prepared in an extracted upper central incisor. Then, a 2-mm layer of composite resin was placed on the floor and polymerized by different PWM modes. Intrapulpal temperature changes were measured using a K-type thermocouple, which was positioned at the pulp-dentin junction of the sample tooth and connected to a digital thermometer (TM-917, No. 57453, Lutron, Taiwan, ROC). Data were recorded every five seconds for 40 seconds from the time of light activation. This process was repeated 10 times for each PWM mode.

\section{Optimal PWM mode}

To find the optimal PWM mode, we considered a plot of the irradiance on the $\mathrm{X}$-axis $\left(\mathrm{mW} / \mathrm{cm}^{2}\right)$ versus the temperature $\left({ }^{\circ} \mathrm{C}\right)$ from 5 to 40 seconds on the $\mathrm{Y}$-axis. A line from (irradiance, temperature) $\left(800 \mathrm{~mW} / \mathrm{cm}^{2}\right.$, $\left.42.5^{\circ} \mathrm{C}\right)$ to $\left(1400 \mathrm{~mW} / \mathrm{cm}^{2}, 42.5^{\circ} \mathrm{C}\right)$ was used as a reference relation between irradiance and temperature of ordinary LCUs. In the present study, we used 42.5 ${ }^{\circ} \mathrm{C}$, the critical temperature for irreversible damage to the pulp ${ }^{6,7)}$, as a reference level that should not be exceeded. The mode with the highest irradiance but a temperature that remained well below the reference line after 40 seconds was chosen as the optimal PWM mode and used in the prototype PWM LED LCU.

Characterization and curing temperature of LED and QTH LCUs

One QTH and four LED LCUs were used in this study (Table 1). The LED LCUs included the Vivadent Bluephase LED (VB), Dentsply SmartLite iQ (DS), Kerr LEDemetron I (KL), and our custommade PWM LED prototype (PWM). We also used the Demetron Optilux 501 (DO), a high-intensity QTH LCU, as a control unit. Light irradiance of the prototype PWM LED LCU and four commercially available LCUs were measured directly from the output of the light guide using the same curing radiometer. Measurement was repeated five times with the LED powered down and reactivated between measurements. 
Temperature changes were also measured from the pulp chamber of the sample tooth, using the same instrument and method as previously described. Temperature data were recorded every five seconds for 40 seconds beginning from the light activation of the high-power LED and QTH LCUs. Temperature change caused by each LCU was plotted in 5-second increments. A line from (irradiance, temperature) $\left(800 \mathrm{~mW} / \mathrm{cm}^{2}, 42.5^{\circ} \mathrm{C}\right)$ to $\left(1400 \mathrm{~mW} / \mathrm{cm}^{2}, 42.5^{\circ} \mathrm{C}\right)$ was drawn as a reference. A digital real-time oscilloscope was used to check that these off-the-shelf devices were indeed continuous wave emitters by measuring the current wave diagrams of the five different LCUs.

\section{Microhardness measurement of composite}

For each LCU, five samples of Z250 composite were cured for 40 seconds in a stainless steel mold with an outer diameter of $16 \mathrm{~mm}$, inner diameter of $4 \mathrm{~mm}$, and a depth of $2 \mathrm{~mm}$. The top and bottom surfaces of the mold were covered with a mylar strip. Samples were stored in the dark at $37^{\circ} \mathrm{C}$ for 24 hours. Microhardness of specimens was measured three times on the bottom surface using a Vickers microhardness tester (MXT-50, Matsuzawa Seiki Co., Tokyo, Japan) at $200 \mathrm{gf}$ load.

\section{Statistical analysis}

In this study, all calculations were performed using

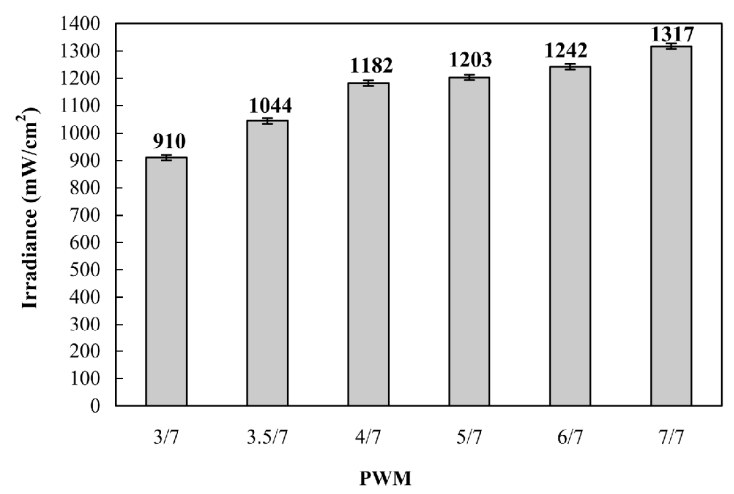

Fig. 3 Irradiance of six different PWM modes measured by digital curing light meter. a statistical analysis software, SAS program JMP version 5.0 (SAS Institute Inc., Cary, NC, USA). Data were compared by ANOVA/Tukey's HSD test and Spearman's correlation coefficient; significance level was set at $\mathrm{p}<0.05$ for each analysis.

\section{RESULTS}

\section{Irradiance for different PWMs}

Fig. 3 shows the irradiance of the six different PWMs. The $7 / 7$ mode had the highest irradiance of 1,317 (1.30) $\mathrm{mW} / \mathrm{cm}^{2}$; the $3 / 7$ mode had the lowest irradiance of $910(1.14) \mathrm{mW} / \mathrm{cm}^{2}$. Analysis with oneway ANOVA indicated that there were statistically significant differences among different PWMs in their irradiance $\left(\mathrm{F}_{5,24}=76862 ; \mathrm{p}<0.0001\right)$. Further analysis with Tukey's HSD test indicated that PWM mode had a significant influence on irradiance $(\mathrm{p}<0.05)$

\section{Optimal PWM mode}

Fig. 4 reveals that the temperature rise of the $7 / 7$ and $6 / 7$ modes were above the $42.5^{\circ} \mathrm{C}$ reference line,

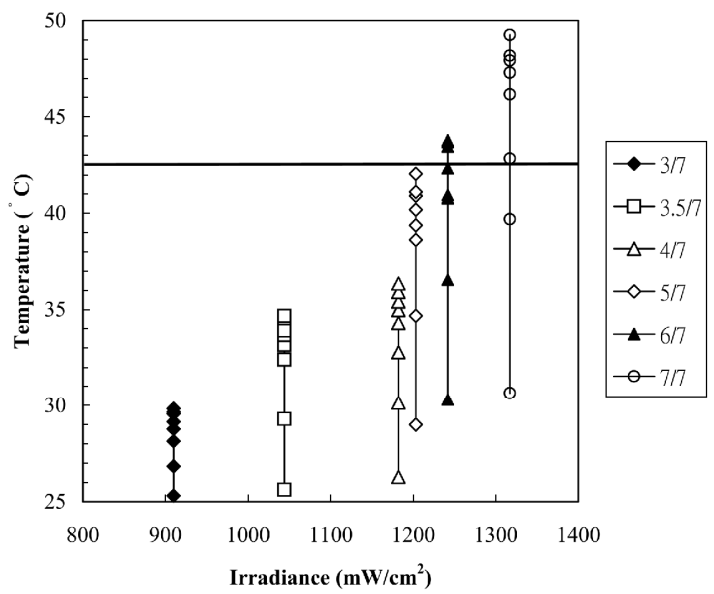

Fig. 4 Reference irradiance-temperature line and measured data showing the relation between irradiance and temperature for six different PWM modes. Symbols along each vertical bar show the temperature at 5 -second intervals from $5 \mathrm{~s}$ to $40 \mathrm{~s}$.

Table 1 Technical details of LCUs used in this study

\begin{tabular}{cccccc}
\hline & $\begin{array}{c}\text { Optilux 501 } \\
\text { Kerr Demetron }\end{array}$ & $\begin{array}{c}\text { SmartLite iQ } \\
\text { Dentsply }\end{array}$ & $\begin{array}{c}\text { LEDemetron I } \\
\text { Kerr Demetron }\end{array}$ & $\begin{array}{c}\text { Bluephase } \\
\text { Vivadent }\end{array}$ & $\begin{array}{c}\text { PWM LED } \\
\text { Prototype }\end{array}$ \\
\hline Light source & 80 Watts QTH & 5 Watts LED & 5 Watts LED & 8 Watts LED & 5 Watts LED \\
Light guide & $\begin{array}{c}\text { Fiber optic } \\
\text { curved turbo }\end{array}$ & $\begin{array}{c}\text { Fiber optic } \\
\text { tapered }\end{array}$ & $\begin{array}{c}\text { Fiber optic } \\
\text { curved }\end{array}$ & $\begin{array}{c}\text { Fiber optic } \\
\text { curved turbo }\end{array}$ & $\begin{array}{c}\text { LED probe } \\
\text { curved }\end{array}$ \\
$\begin{array}{c}\text { Output diameter of } \\
\text { light guide }\end{array}$ & $8 \mathrm{~mm}$ & $8.5 \mathrm{~mm}$ & $8 \mathrm{~mm}$ & $8 \mathrm{~mm}$ & $8 \mathrm{~mm}$ \\
Serial number & 5820050 & 619705859 & 71004280 & 1528034 & Custom-made \\
\hline
\end{tabular}


and that the $5 / 7$ mode was under but very close to the line. The $4 / 7$ mode was found to have the optimal PWM combination of high irradiance at 1,182 (1.30) $\mathrm{mW} / \mathrm{cm}^{2}$ but low final temperature of 36.35 $(0.39)^{\circ} \mathrm{C}$ - which was far below the higher irradiance modes. Analysis with two-way ANOVA indicated that there were statistically significant differences among the different PWMs $\left(\mathrm{F}_{5,12}=2730 ; \mathrm{p}<0.0001\right)$ and different curing times $\left(\mathrm{F}_{7,12}=497.8 ; \mathrm{p}<0.0001\right)$. A significant interaction effect $\left(\mathrm{F}_{35,12}=18.2 ; \mathrm{p}<\right.$ 0.0001) was also found between PWM and curing time. Further analysis with Tukey's HSD test indicated that irradiance and temperature rise over each time period were significantly different for different PWM modes $(p<0.0001)$. By utilizing the Spearman's correlation coefficient, we found that the irradiance and temperature rise for all PWM modes were statistically significant $(\mathrm{p}<0.0001)$ and strongly positive $(\mathrm{r}=0.9466, \mathrm{p}<0.0001)$.

\section{Irradiance and temperature change for different LCUs}

Fig. 5 compares the irradiance of the prototype PWM LED LCU with the various high-power LCUs. KL had the highest irradiance of $1,226(1.48) \mathrm{mW} / \mathrm{cm}^{2}$; DS had the lowest irradiance of $869(0.84) \mathrm{mW} / \mathrm{cm}^{2}$. As for the conventional QTH LCU, DO, its irradiance was $906(1.92) \mathrm{mW} / \mathrm{cm}^{2}$.

Fig. 6 reveals that the final temperature reached by VB, KL, DS, and DO LCUs were above the 42.5 ${ }^{\circ} \mathrm{C}$ reference line. However, the final temperature of the prototype PWM LED LCU was below the reference line. $\mathrm{VB}$ had the highest final temperature of $48.74(1.23){ }^{\circ} \mathrm{C}$; PWM had the lowest final temperature of $36.35 \quad(0.39){ }^{\circ} \mathrm{C}$. Analysis with two-way ANOVA indicated that there were statistically significant differences among the different LCUs $\left(\mathrm{F}_{4,20}\right.$ $=1004 ; \mathrm{p}<0.0001)$ and different curing times $\left(\mathrm{F}_{7,20}\right.$ $=428 ; \mathrm{p}<0.0001)$. A significant interaction effect $\left(\mathrm{F}_{28,20}=11 ; \mathrm{p}<0.0001\right)$ was also found between LCU and curing time. Further analysis with Tukey's HSD tests indicated that different LCUs and curing times had significant influences in temperature change

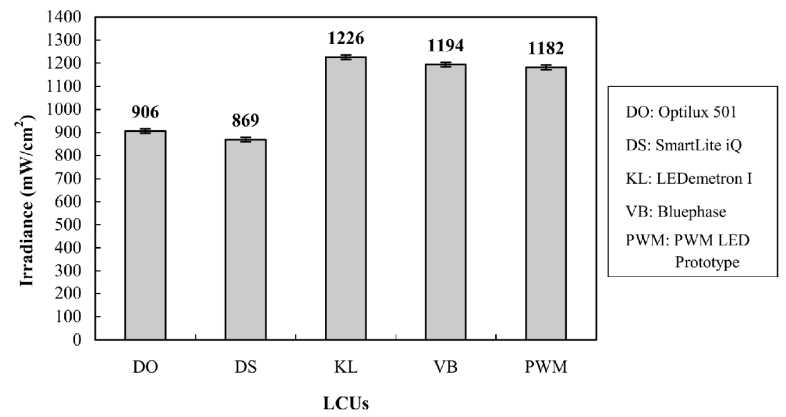

Fig. 5 Irradiance of one QTH and four LED LCUs measured by a digital curing light meter. $(\mathrm{p}<0.0001)$.

\section{Microhardness measurement of composite}

Fig. 7 shows the Vickers hardness on the bottom surface of composite samples after 40-second polymerization with different LCUs. The prototype PWM LED LCU had the highest VHN of 76.28 (0.86); KL had the lowest VHN of 69.52 (0.37). One-way ANOVA and Tukey's HSD pairwise test indicated that Vickers hardness values were significantly different for PWM prototype and $\mathrm{VB}$ versus $\mathrm{DO}$, DS, and $\mathrm{KL}(\mathrm{p}<$ 0.0001).

\section{DISCUSSION}

Pulse width modulation (PWM) is an effective method to control light irradiance and temperature rise in LEDs. The influences of heat from light irradiance on pulp tissue were mentioned in previous studies, but the effect and benefits of LED-emitted irradiance were overlooked ${ }^{10,11)}$. In practical applica-

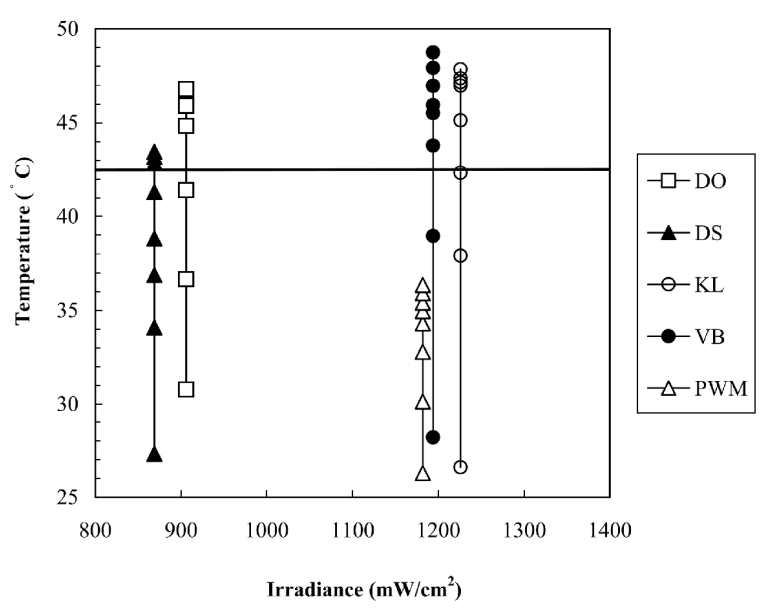

Fig. 6 Reference irradiance-temperature line and measured data showing the relation between irradiance and temperature for five different LCUs. Symbols along each vertical bar show the temperature at 5second intervals from $5 \mathrm{~s}$ to $40 \mathrm{~s}$.

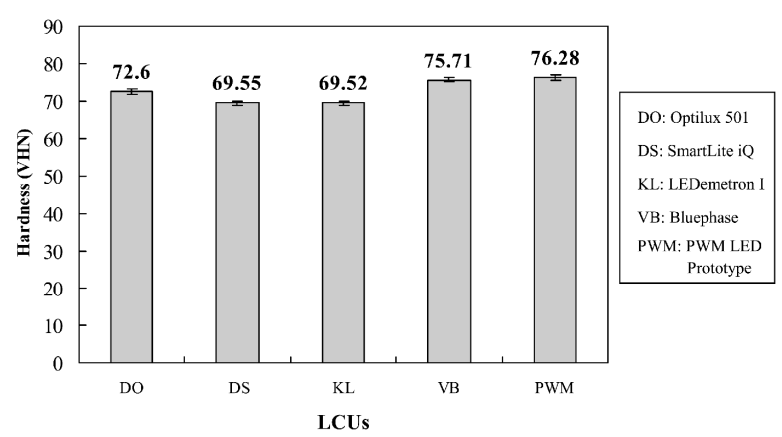

Fig. 7 Vickers hardness numbers of the bottom surface of composite samples after 40-second curing using different high-power LCUs. 
tions, both irradiance and temperature rise of highpower LEDs are very important considerations. The chief benefit of pulsed laser use in medical applications is that the periodic interruption of the light beam allows the target material to cool between laser pulses, thus preventing overheating ${ }^{26-28)}$. With pulse width modulation, the current output and time cycle of an LED can be easily controlled, such that the desired pulse can be obtained with an instant output of high power ${ }^{25)}$. From a previous report on dental composite polymerization by blue laser light, the laser pulse energy released by a pulsed blue laser was $10 \mathrm{~mJ}$ per pulse, with a duration of $20 \mathrm{~ns}$ and a repetition rate of $10 \mathrm{~Hz}^{23)}$. By comparison, the prototype PWM with a 12-ms-on/9-ms-off pulse duration, a light irradiance of $1,182(1.30) \mathrm{mW} / \mathrm{cm}^{2}$, and a LED emitting area of $8 \mathrm{~mm}$ diameter had an output power of:

$$
1,182 \mathrm{~mW} / \mathrm{cm}^{2} \times \pi(0.4 \mathrm{~cm})^{2} \approx 594 \mathrm{~mW}
$$

Since the PWM period was $21 \mathrm{~ms}$, energy per pulse was therefore:

$$
594 \mathrm{~mW} \times 21 \mathrm{~ms} \approx 12.5 \mathrm{~mJ}
$$

To estimate the peak power, the following equation was used:

$$
\mathrm{P}_{\mathrm{p}}=\frac{\mathrm{Pa}}{\text { Pulse }}
$$

The peak power, $\mathrm{P}_{\mathrm{p}}$, emitted during 12 out of $21 \mathrm{~ms}$ would therefore be equivalent to:

$$
594 \mathrm{~mW} \times 21 \div 12 \approx 1.04 \mathrm{~W} \text { continuous wave }
$$

As for KL, the commercial LCU with the highest irradiance of $1,226(1.48) \mathrm{mW} / \mathrm{cm}^{2}$ and an LED emitting area of $8 \mathrm{~mm}$ diameter, its output power was:

$$
1,226 \mathrm{~mW} / \mathrm{cm}^{2} \times \pi(0.4 \mathrm{~cm})^{2} \approx 0.62 \mathrm{~W} \text { continuous }
$$
wave

The output powers of the other high-power LCUs were $0.6 \mathrm{~W}$ for $\mathrm{VB}, 0.49 \mathrm{~W}$ for $\mathrm{DS}$, and $0.46 \mathrm{~W}$ for DO - as calculated Equation (5). In this study, the optimal LED PWM mode was the $4 / 7$ mode. By incorporating this optimal PWM mode into an LCU for the polymerization of oral biomaterials, the previously mentioned problem concerning high temperatures caused by high-power LEDs would be solved. At the same time, this was not done at the expense of power density. As shown from Equations (4) and (5), the optimal PWM mode delivered a peak power equivalent to $1.0 \mathrm{~W}$ continuous wave, as compared to other high-power LED and QTH LCUs. As for VB, KL, DS, and DO LCUs, their final temperatures after 40 seconds were significantly higher than the noncontinuous prototype PWM LED LCU. While the exact temperature will be inevitably and understandably different in a clinical situation, the key point is that our prototype LCU had a significantly lower final temperature.

Temperature rise arising from high irradiance is a potential hazard for the pulp of teeth. In 1958, Pohto and Scheinin ${ }^{7)}$ indicated that the critical temperature for irreversible damage to the pulp began at $42-42.5^{\circ} \mathrm{C}$. In 1994 , Närhi et $a l^{29)}$ indicated that when heat was applied long enough to increase the temperature of the dentin-pulp border by several degrees Celsius, the intradental C-fibers might respond - especially if the heat produced tissue injury. Conversely, slow heating of the tooth produced no response until the temperature reached $43.8^{\circ} \mathrm{C}$. In 2003 , O'Neil and Brown ${ }^{30}$ indicated that the transient receptor potential vallinoid 1 (TRPV1) receptor is expressed primarily on a major subclass of nociceptors and responds to heat over $43{ }^{\circ} \mathrm{C}$. Based on the reports cited herein, $42.5^{\circ} \mathrm{C}$ was adopted as the limiting temperature that the pulp could tolerate - that is, the reference point - in this study.

It has been shown that the microhardness of a composite has good correlation with the degree of monomer conversion ${ }^{16)}$. Therefore, a composite with a lower microhardness value indicates a lower degree of conversion and therefore lower irradiation by LED LCU. In this study, PWM yielded the highest Vickers hardness in 2-mm composites after 40 seconds of curing. Data also showed that the prototype PWM LED LCU had a lower temperature rise than the other LCUs but still maintained a high output power, which was effective in composite polymerization.

High-power LED LCUs were reported to have a higher irradiance than some of the conventional QTH LCUs, as was shown in our data. Using a digital real-time oscilloscope, we confirmed that all the current wave diagrams of $\mathrm{VB}, \mathrm{KL}, \mathrm{DS}$, and $\mathrm{DO}$ showed a continuous wave. Among these LCUs, the prototype PWM LED LCU caused a significantly lower temperature rise than the other dental LCUs, and may thus eliminate the problem noted in recent papers $^{21,22)}$ concerning the heating of pulp tissue and oral biomaterials. As for the conventional QTH Demetron 501 control unit, it showed continuous wave emission and high heat generation. For this halogen light source, despite its lower light irradiance relative to the PWM LED, the temperature change after 40 seconds was significantly higher than some of the LED LCUs.

High-power LED with PWM operation can maintain a high output power and have a lower temperature rise during curing. When considering the adverse influence on pulp tissue and oral biomaterials, the PWM LED would be a more expedient design for dental light curing devices. Moreover, the design of the prototype PWM LED LCU was enhanced by placing the LED at the front instead of transmitting light pulses through the optical fiber, as in the other LCUs. The front-mounted LED LCU therefore 
circumvents the light transmission loss through optical fiber if the LED were placed at the rear. However, further studies and research with the prototype light curing unit are required to investigate its effect on curing depth and material shrinkage with different types of composite.

\section{CONCLUSION}

Light irradiance of a high-power LED is higher than ordinary LED and QTH lights, but the risk of high temperature rise during light emission poses a problem. Using the PWM method to modulate the output of high-power LED in a time domain, the LED light could maintain a relatively high irradiance but with lower heat generation. At least for the polymerization of the composite resin Z250, the optimal PWM mode identified in the present study might be able to reduce the risk of pulp damage associated with the high heat of third-generation, high-power LED LCUs.

\section{ACKNOWLEDGEMENTS}

The authors gratefully acknowledge the technical support rendered by Dentamerica Inc. (Industry, CA USA). We are also grateful to Dentsply DeTray, Kerr Demetron, and Ivoclar Vivadent for their supply of dental LCUs, and to Theodore Hsu and Eric Huang for their help on reviewing this article.

\section{REFERENCES}

1) Hannig M, Bott B. In-vitro pulp chamber temperature rise during composite resin polymerization with various light-curing sources. Dent Mater 1999; 15: 275-281.

2) Loney RW, Price RBT. Temperature transmission of high-output light-curing units through dentin. Oper Dent 2001; 26: 516-520.

3) Kleverlaan CJ, de Gee AJ. Curing efficiency and heat generation of various resin composites cured with high-intensity halogen lights. Eur J Oral Sci 2004; 112: 84-88.

4) Wataha J, Lockwood P, Lewis J, Rueggeberg F, Messer R. Biological effects of blue light from dental curing units. Dent Mater 2004; 20: 150-157.

5) Danesh G, Davids H, Duda S, Kaup M, Ott K, Schafer E. Temperature rise in the pulp chamber induced by a conventional halogen light-curing source and a plasma arc lamp. Am J Dent 2004; 17: 203-208.

6) Zach L, Cohen G. Pulp response to externally applied heat. Oral Surg 1965; 19: 515-530.

7) Pohto M, Scheinin A. Microscopic observation on living dental pulp. Acta Odontol Scand 1958; 16: 303-327.

8) Hansen EK, Asmussen E. Correlation between depth of cure and temperature rise of light-activated resin. Scand J Dent Res 1993; 101: 176-179.

9) Nakamura S, Mukai T, Senoh M. High-power GaN P$\mathrm{N}$ junction blue light emitting diodes. Jpn J Appl
Phys 1991; 30: L1998-L2001.

10) Tarle Z, Meniga A, Knezevic A, Sutalo J, Ristic M, Pichler G. Composite conversion and temperature rise using a conventional, plasma arc and an experimental blue LED curing unit. J Oral Rehab 2002; 7: 662-667.

11) Yap AUJ, Soh MS. Thermal emission by different light-curing units. Oper Dent 2003; 28: 260-266.

12) Uhl A, Mills R, Jandt K. Polymerization and lightinduced heat of dental composites cured with LED and halogen technology. Biomaterials 2003; 24: 1809-1820.

13) Hofmann N, Hugo B, Klaiber B. Effect of irradiation type (LED or QTH) on photo-activated composite shrinkage kinetics, temperature rise, and hardness. Eur J Oral Sci 2002; 6: 471-479.

14) Nomura $Y$, Teshima W, Tanaka N, Yoshida $Y$, Nahara Y, Okazaki M. Thermal analysis of dental resins cured with blue light-emitting diode (LEDs). J Biomed Mater Res 2002; 2: 209-213.

15) Mills RW, Uhl A, Blackwell GB, Jandt KD. High power light emitting diode (LED) arrays versus halogen light polymerization of oral biomaterials: Barcol hardness, compressive strength and radiometric properties. Biomaterials 2002; 23: 2955-2963.

16) Uhl A, Sigusch B, Jandt K. Second generation LEDs for the polymerization of oral biomaterials. Dent Mater 2004; 20: 80-87.

17) Teshima W, Nomura $Y$, Tanaka N, Urabe H, Okazaki M, Nahara Y. ESR study of camphorquinone/amine photoinitiator systems using blue light-emitting diodes. Biomaterials 2003; 24: 2097-2103.

18) LUMILEDS Lighting. San Jose, California, USA.

19) Bouillaguet S, Caillot G, Forchelet J, Cattani-Lorente M, Wataha JC, Krejci I. Thermal risks from LED- and high-intensity QTH-curing units during polymerization of dental resins. J Biomed Mater Res 2005; 72: 260-267.

20) Ozturk B, Ozturk AN, Usumez A, Usumez S, Ozer F. Temperature rise during adhesive and resin composite polymerization with various light curing sources. Oper Dent 2004; 29: 325-332.

21) Bouschlicher M, Montes S, Qian F. Intrapulpal temperature increases with high intensity LED curing lights. J Dent Res 2004; Abstract No. 1875.

22) Asmussen E, Peutzfeldt A. Temperature rise induced by some light emitting diode and quartz-tungstenhalogen curing units. Eur J Oral Sci 2005; 1: 96-98.

23) Meniga A, Tarle Z, Ristic M, Sutalo J, Pichler G. Pulsed blue laser curing of hybrid composite resins. Biomaterials 1997; 18: 1349-1354.

24) Hitz B. Understanding LASER technology, PennWell Publishing Co., Oklahoma, 1985, pp.137-142.

25) Barr M. Introduction to pulse width modulation. In: Embedded systems programming, CMP Books, Kansas, 2001, pp.103-104.

26) Rechmann $\mathrm{P}$. The $\mathrm{CO}_{2}$ laser in oral surgery, Vol. 2, DPL Co., Queensland, 2003, pp.3-11.

27) Cobb DS, Dederich DN, Gardner TV. In vitro temperature change at the dentin/pulpal interface by using conventional visible light versus argon laser. Lasers Surg Med 2000; 26: 386-397.

28) Powell GL, Anderson JR, Blankenau RJ. Laser and 
curing light induced in vitro pulpal temperature changes. J Clin Laser Med Surg 1999; 17: 3-5.

29) Närhi M, Yamamoto H, Ngassapa D, Hirvonen T. The neurophysiological basis and the role of inflammatory reactions in dentine hypersensitivity. Arch Oral Biol
1994; 39: 238.

30) O'Neil RG, Brown RC. The vanilloid receptor family of calcium-permeable channels: Molecular integrators of microenvironmental stimuli. News Physiol Sci 2003; 18: 226. 